\title{
Dissemination of CTX-M-Producing Escherichia coli in Freshwater Fishes From a French Watershed (Burgundy)
}

\author{
Loic Bollache ${ }^{1,2}$, Emeline Bardet ${ }^{2}$, Géraldine Depret ${ }^{2}$, Sébastien Motreuil ${ }^{3}$, \\ Catherine Neuwirth ${ }^{4}$, Jérome Moreau ${ }^{3}$ and Alain Hartmann ${ }^{2 *}$
}

' UMR CNRS 6249, Laboratoire Chrono-Environnement, Besançon, France, ${ }^{2}$ Agroécologie, AgroSup Dijon, INRA, Université de Bourgogne, Université de Bourgogne Franche-Comté, Dijon, France, ${ }^{3}$ UMR CNRS 6282 Biogéosciences, Laboratoire Biogéosciences, Dijon, France, ${ }^{4}$ Bacteriology Department, University Hospital, Université de Bourgogne Franche-Comté, Dijon, France

\section{OPEN ACCESS}

Edited by:

Sebastian Guenther, University of Greifswald, Germany

Reviewed by:

Jean-Yves Madec,

Agence Nationale de Sécurité

Sanitaire de l'Alimentation,

de l'Environnement et du Travail (ANSES), France

Stephen E. Mshana,

Catholic University of Health and Allied Sciences (CUHAS),

Tanzania

*Correspondence: Alain Hartmann

alain.hartmann@inra.fr

Specialty section:

This article was submitted to Antimicrobials, Resistance

and Chemotherapy,

a section of the journa

Frontiers in Microbiology

Received: 14 September 2018 Accepted: 13 December 2018

Published: 08 January 2019

Citation:

Bollache L, Bardet E, Depret G, Motreuil S, Neuwirth C, Moreau J and

Hartmann A (2019) Dissemination of CTX-M-Producing Escherichia coli in Freshwater Fishes From a French

Watershed (Burgundy).

Front. Microbiol. 9:3239.

doi: 10.3389/fmicb.2018.03239
The burden of extended-spectrum $\beta$-lactamases producing Escherichia coli (ESBL-EC), has increased over several decades. Freshwater ecosystems are suspected to play an important ecological and evolutionary role in driving the dissemination of antimicrobial resistance. The aim of our study was to decipher the occurrence of ESBL-EC in a small watershed (Ouche river, Burgundy, France), targeting environmental matrices and fishes. Among cefotaxime resistant $E$. coli (ctxR $E_{C}$ ) isolates, we detected and characterized 36 ESBL-Ec from water, biofilm and fish guts. ctxR Ec and ESBL-Ec were found in samples from sites near the first small town, located downstream from the watershed which was studied. Treatment of urban wastewater by waste water treatment plants (WWTP), might therefore be a major potential source of ctxR EC and thus of ESBL-EC. Prevalence of total E. coli and ctxR EC in fish guts ranged between 0 to $92 \%$ and 0 to $85 \%$; respectively, depending on the sampling site and the fish species. The diet of fish (predator or omnivore) seems to strongly influence the prevalence of total $E$. coli and ESBL-Ec. Extended spectrum beta-lactamases produced by the isolates from this study belonged to the CTX-M family (CTX-M group 1 and 9). Moreover, some environmental ESBL-EC proved to share genotypic features (MLST types) with isolates which originated from 8 WWTP effluents discharged in the Ouche river and with the sequence type ST131, which is widely described in clinical isolates. Ninety-seven \% (97\%) of ESBL$E_{C}$ from the study harbored additional antibiotic resistances and can thus be considered as multi drug resistant (MDR) bacteria. Finally, 53\% of the ESBL-EC strains harbored class 1 integron-integrase (int/1). These results are discussed with the perspective of defining indicators of antibiotic resistance contamination in freshwater ecosystems.

Keywords: freshwater, ESBL producing Escherichia coli, bla $\mathrm{CTX}-\mathrm{M}$, class 1 integron-integrase, antibiotic resistance, fish, MLST E. coli

\section{INTRODUCTION}

Dissemination of extended-spectrum $\beta$-lactamases (ESBLs) among Enterobacteriaceae (especially by Escherichia coli) has dramatically increased among human populations (in community and hospital settings) over several decades and is recognized worldwide as a major public health concern (Woerther et al., 2010). With increasing numbers of ESBL-producing bacteria in healthcareassociated and community-acquired infections, ESBL-producers have become one of the most 
important groups of multi-drug-resistant (MDR) bacteria involved in healthcare-associated infections caused by E. coli or other enterobacteria (Bonnet, 2004).

First described in 1989, the CTX-M type ESBL is nowadays the most prevalent clinical isolate worldwide (Livermore and Hawkey, 2005) but also the most prevalent in human and animal feces (Guenther et al., 2011), in sewage sludge (Reinthaler et al., 2010), in soils (Hartmann et al., 2012) and in aquatic environments (Zurfluh et al., 2013; Blaak et al., 2014; Maravic et al., 2015). Effluents discharged into aquatic ecosystems, by waste water treatment plants (WWTP) treating urban and hospital wastewater, have been clearly identified as a source of extended-spectrum $\beta$-lactamases producing Escherichia coli $(\mathrm{ESBL}-E \mathrm{c})$ that are disseminated in aquatic environments (Brechet et al., 2014; Blaak et al., 2015; Franz et al., 2015).

Whereas mechanisms conferring resistance to many antibiotic families in bacteria are well understood (Tenover, 2006; Stokes and Gillings, 2011), the processes facilitating persistence and dissemination of ESBL-producing bacteria in the environment have been less intensively studied.

Among ecological and environmental factors contributing to the environmental spread of antimicrobial resistant bacteria, the epidemiological role of wild fauna as reservoirs or transporters of resistant bacteria, has been repeatedly emphasized. Thus, ESBL-Ec strains have been reported in many wild species, particularly in wild bird populations living in areas inhabited by people (Bonnedahl et al., 2009, 2010; Literak et al., 2010; Poirel et al., 2012; Vittecoq et al., 2016; Mohsin et al., 2017; Carter et al., 2018) and mammals (Costa et al., 2006; Literak et al., 2009; Goncalves et al., 2012). Therefore, the role of the environment and especially aquatic ecosystems, has to be assessed with regards to the emergence of resistant bacteria like ESBL-Ec (Taylor et al., 2011; Marti et al., 2014). Marine and freshwater ecosystems are known to receive numerous chemical and biological contaminants, among those antibiotic residues and antibiotic resistant bacteria are released in aquatic ecosystems through discharge from livestock and WWTP. However, the spread of ESBL-Ec into freshwater ecosystems and the role of fishes in this process have received little attention (Tacao et al., 2012; Pereira et al., 2013). Indeed, fishes are mobile, have different feeding habits and use various microhabitats in the river (Popova and Sytina, 1977; Hyslop, 1982; Weatherley, 1987; Garner, 1996), thus freshwater fishes might also disseminate ESBL-Ec through their movements and might serve as integrators of a freshwater ecosystems bacterial contamination. Indeed, recently several authors have documented the contamination of wild fish in marine environments (Brahmi et al., 2018) and in lakes (Abgottspon et al., 2014; Zurfluh et al., 2015; Moremi et al., 2016) as well as in farmed fish (Jiang et al., 2012; Hon et al., 2016), stressing that fishes could participate in the spread of multidrug resistant enterobacteria. However, such data is missing for fishes from rivers and streams.

Finally, freshwater might constitute an efficient vector for the spread of antibiotic resistance through various ways: i.e., irrigation of cultures or drinking water for livestock animals. Thus, freshwater ecosystems are suspected to play an important ecological and evolutionary role in driving the emergence, persistence and dissemination of antimicrobial resistance (Taylor et al., 2011), and to become a reservoir potentially leading to human contamination through water, food consumption or recreational activities (Leverstein-van Hall et al., 2011; Schijyen et al., 2015). In this context, it is important to determine how these bacteria have spread to freshwater ecosystems and their associated fauna as well as to understand the role of human activities in the occurrence of contamination. Concerning freshwater fauna, this study targets fishes occurring naturally in river ecosystems.

The objectives of the study were to evaluate (i) the occurrence of ESBL-Ec strains in freshwater fishes and their natural environment (water and biofilm), collected at several sites of the Ouche watershed (Burgundy, France), (ii) the diversity of ESBL-Ec from fishes and their environment (MLST typing), their antibiotic susceptibility and the prevalence of bla genes as well as the occurrence of class 1 integrons, in the isolates. The genetic diversity of environmental ESBL-Ec strains was compared with that observed in a collection of ESBL-Ec strains isolated from effluents of eight WWTP, discharging into the Ouche watershed.

\section{MATERIALS AND METHODS}

\section{Sites Studied Along the Ouche River and Sampling Methods}

In spring 2012, 14 sampling sites were defined along the river Ouche (Burgundy, Eastern France), from the spring to the Saône confluence (Figure 1, site 1: Lusigny-surOuche $47^{\circ} 05^{\prime} 25.2^{\prime \prime} \mathrm{N} 4^{\circ} 40^{\prime} 22.0^{\prime \prime} \mathrm{E}$, site 2: Bligny-sur-Ouche, site 3: Bligny-sur-Ouche $47^{\circ} 06^{\prime} 34.6^{\prime \prime} \mathrm{N} \quad 4^{\circ} 39^{\prime} 58.2^{\prime \prime} \mathrm{E}$, site 4: Pont d'Ouche $47^{\circ} 10^{\prime} 02.1^{\prime \prime} \mathrm{N} 4^{\circ} 42^{\prime} 02.7^{\prime \prime} \mathrm{E}$, site 5: Pont de Pany $47^{\circ} 17^{\prime} 49.9^{\prime \prime} \mathrm{N} 4^{\circ} 48^{\prime} 47.5^{\prime \prime} \mathrm{E}$, site 6: Mâlain $47^{\circ} 19^{\prime} 18.1^{\prime \prime} \mathrm{N}$ $4^{\circ} 48^{\prime} 22.4^{\prime \prime} \mathrm{E}$, site 7 : Plombières $47^{\circ} 19^{\prime} 40.8^{\prime \prime} \mathrm{N} 4^{\circ} 59^{\prime} 16.8^{\prime \prime} \mathrm{E}$, site 8: Dijon $47^{\circ} 17^{\prime} 41.1^{\prime \prime} \mathrm{N} 5^{\circ} 02^{\prime} 50.0^{\prime \prime} \mathrm{E}$, site 9: Dijon $47^{\circ} 17^{\prime}$ $11.761^{\prime \prime} \mathrm{N}, 5^{\circ} 04^{\prime} 59.883^{\prime \prime} \mathrm{E}$, site 10 : Varanges $47^{\circ} 13^{\prime} 59.4^{\prime \prime} \mathrm{N}$ $5^{\circ} 11^{\prime} 58.2^{\prime \prime} \mathrm{E}$, site 11: Tart l'Abbaye $47^{\circ} 10^{\prime} 55.1^{\prime \prime} \mathrm{N} 5^{\circ} 15^{\prime} 08.2^{\prime \prime} \mathrm{E}$, site 12: Trouhans $47^{\circ} 08^{\prime} 54.8^{\prime \prime} \mathrm{N} 5^{\circ} 16^{\prime} 38.8^{\prime \prime} \mathrm{E}$, site 13: SaintJean-de-Losne (Saône river) $47^{\circ} 06^{\prime} 03.4^{\prime \prime} \mathrm{N} 5^{\circ} 15^{\prime} 58.9^{\prime \prime} \mathrm{E}$, site 14: Saint-Jean-de-Losne (harbor) $47^{\circ} 06^{\prime} 08.2^{\prime \prime} \mathrm{N} 5^{\circ} 15^{\prime} 35.0^{\prime \prime} \mathrm{E}$ ). For all sites, $500 \mathrm{~mL}$ of water were collected $(0.5 \mathrm{~m}$ from the shore and between 20 to $50 \mathrm{~cm}$ depth). One to $5 \mathrm{~g}$ of epilithon or biofilm were collected directly from the stone surface and from aquatic plants, using a sterile single use blade to prevent cross contaminations between sites. Fishes were sampled (one campaign) only from the sites eight and nine using battery-powered portable electrofishing gear (Dream Électronique Society, France). All fishes were maintained in aerated $40 \mathrm{~L}$ plastic tanks until their arrival at the laboratory. Within $4 \mathrm{~h}$ after collection, fishes were identified to the species level according to Keith and Allardi (2001) and measured (fork length). A total of 14 water samples, 16 biofilm samples and 127 fish samples were collected and used for further microbiological analyses as described below. The locations of the eight WWTP discharging treated effluents into the Ouche river are available in Figure 1. 


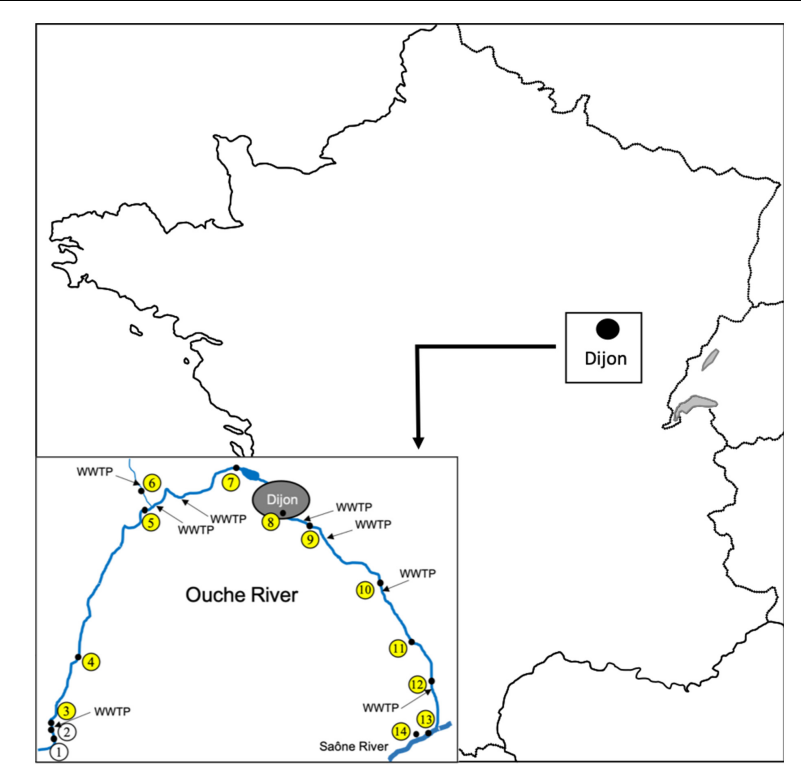

FIGURE 1 | Location and map of Ouche river watershed, the position of the sampling sites is indicated by their numbers within open circles as described in Table 1, yellow colored circles indicate positive sites for the presence of ctxR Ec. Locations of eight WWTP discharging into the Ouche river are indicated by arrows. The bar represents a $5 \mathrm{~km}$ distance.

\section{Detection, Enumeration and Isolation of Total E. coli and Cefotaxim Resistant E. coli (ctxR Ec) From Water, Biofilm Samples and From Fish Guts}

Water sample processing: Four hundred milliliters of water samples were filtered on HAWP cellulose ester filters (porosity $0.45 \mu \mathrm{m}$ ) (Merck Millipore, Germany). Filters were then washed into $5 \mathrm{~mL}$ of buffered peptone water (BPW) (AES Chemunex, bioMérieux France) and mixed vigorously with a vortex to resuspend bacteria.

Biofilm sample processing: Epilithon and biofilm samples were resuspended in $5 \mathrm{~mL}$ of BPW and homogenized by vigorous shaking.

Fish sample processing: Fishes were anesthetized and gutted using aseptic techniques immediately upon arrival at the laboratory. The fish guts were then rinsed with sterile BPW. Guts were ground and homogenized in $1 \mathrm{~mL}$ of BPW by adding $0.1 \mathrm{~g}$ of $106 \mu \mathrm{m}$ diameter glass beads (Sigma-Aldrich, United States) and vortexed for $2 \mathrm{~min}$. The homogenized gut suspension was diluted with $9 \mathrm{~mL}$ of BPW.

Then, $100 \mu \mathrm{L}$ of BPW suspensions which originated from either water, biofilms and homogenized gut samples were spread onto Tryptone Bile X-glucuronide agar plates (AES Chemunex, bioMérieux France), supplemented or not with $4 \mathrm{mg} / \mathrm{L}$ of cefotaxime (Sigma-Aldrich, United States), in order to detect and enumerate ctxR $E c$ and the total E. coli, respectively. Plates were incubated at $37^{\circ} \mathrm{C}$ for $18 \mathrm{~h}$. To maximize the sensitivity of the detection of $c t x R E c$, a non-selective enrichment step was added: i.e., the remaining BPW suspensions were incubated at $37^{\circ} \mathrm{C}$ for $24 \mathrm{~h}$ and then $100 \mu \mathrm{l}$ of this enrichment were plated as described above. After incubation, blue colonies (glucuronidase positive colonies) were counted. For enriched samples, results were expressed as positive (presence of blue colonies) or negative (absence of blue colonies).

For each (enriched or not) plate, 3 ctxR isolates were randomly picked up and purified twice on TBX, supplemented with cefotaxime $(4 \mathrm{mg} / \mathrm{L})$ plates. Isolates were stored at $-80^{\circ} \mathrm{C}$ in a Luria Bertani medium (AES Chemunex, bioMérieux France) supplemented with $25 \%$ glycerol.

\section{Phenotypic Characterization and Antibiotic Resistance Testing of ctxR Ec}

Cefotaxim resistant isolates were confirmed to belong to the E. coli species, by testing their capacity to ferment lactose on Drigalski agar media (Conda, Spain) and by testing on an API 20E test kit (AES Chemunex, bioMérieux France). Some isolates were also identified by MALDI-TOF analysis (MALDI Biotyper, Brucker, France).

The antibiotic susceptibility tests were performed by the disk diffusion method. Susceptibility to 16 antibiotics, including penicillin (aminopenicillin with clavulanic acid), cephalosporins (cefotaxime and ceftazidime), cephamycin (cefoxitin), carbapenems (imipenem and ertapenem), aminoglycosides (kanamycin, tobramycin, gentamycin, streptomycin, and spectinomycin), chloramphenicol, quinolones (nalidixic acid, ofloxacin), tetracycline (doxycycline), and cotrimoxazol was determined for all recovered $E$. coli isolates (CLSI, 2012a). The production of ESBL was assessed by the double-disk synergy test (Jarlier et al., 1988). Isolates were classified as susceptible or resistant to the drug (isolates showing intermediate susceptibility were considered as resistant) according to the Clinical and Laboratory Standards Institute guidelines (CLSI, 2012b).

\section{Characterization of ESBL-Ec by MLST, Detection and Sequencing of bla Genes, as Well as Occurrence of Class 1 Integrons (detection of int/1) Among These Isolates}

DNA of each positive isolate for the production of ESBL was obtained using a rapid extraction method, i.e., boiling $500 \mu \mathrm{L}$ of a dense culture suspension of each strain and recovering the supernatant after a $5 \mathrm{~min}$ centrifugation at $13000 \mathrm{~g}$. ESBL-Ec were characterized by MLST according the recommendations of Wirth et al. (2006) by amplifying seven house-keeping genes. The PCR fragments were then sequenced according to the Sanger method by Genewiz (Takeley, United Kingdom) and the obtained sequences were analyzed with GeneDoc software (Nicholas and Nicholas, 1997). The alleles and sequence types (ST) were assigned according the E. coli MLST website ${ }^{1}$ (Alikhan et al., 2018). All E. coli MLST data was deposited at Enterobase.

A phylogenetic tree (Multiple Spanning tree, MS Tree) based on the different ST isolated from water, biofilm and fish gut was obtained with the package available at the Enterobase database

${ }^{1}$ http://enterobase.warwick.ac.uk/species/index/ecoli 
(Zhou et al., 2017). This phylogenetic tree was displayed and annotated with the online tool iTOL (Letunic and Bork, 2016). For comparison, ESBL-Ec strains isolated from effluents of eight WWTP discharging into the Ouche river, over the same period of time, were included in the tree (Hartmann personal communication, ANSES PNREST CIREC grant 2013-1-254).

qPCR conditions, primers and probes used for the amplification of the bla $a_{C T X}-M$ genes coding CTX-M group 1 and CTX-M group 9 have been previously described (Sabate et al., 2002; Hartmann et al., 2012). The occurrence of class 1 integrons among ESBL-Ec strains was estimated by PCR using primers L2 and L3 as previously described (Maguire et al., 2001). Five PCR products were sequenced to confirm the identity with intl1 sequence. All PCR products were sequenced according to the Sanger method by Genewiz (Takeley, United Kingdom), and compared with those available in the GenBank database using the Blast algorithm ${ }^{2}$. Sequences were deposited in the GenBank database under accession numbers MF926412 through MF926422, MF977504 through MF977517, MF977541 through MF977549 and MG029088, MG029089 for bla $C T X-M$ genes and MF769720, MF769721, MF769722, MF769723, MF769724 for intl1 gene.

\section{Statistical Analyses}

Differences in the prevalence of $c t x R E c$ and total $E$. coli between fish species and fish groups were tested using Fisher's exact test, to compare the proportion of infected individuals between the two sites, or the proportion between the two groups consisting of omnivorous species and predator species, according to their

${ }^{2}$ http://blast.ncbi.nlm.nih.gov/Blast.cgi diets as defined by Keith and Allardi (2001). All analyses were performed with JMP software v. 5.01 (SAS Institute Inc., Cary, NC, United States).

\section{RESULTS}

\section{Distribution of ctxR Ec in Environmental Samples (Water and Biofilm) Along the Ouche River}

Twelve out of 14 sites were positive for the presence of ctxR $E c$ (yellow dots in Figure 1) in the water sample and nine sites were positive for the biofilm samples (Table 1). Only the two first sampling sites on the Ouche river, located upstream from the first small town, i.e., Bligny-sur-Ouche, didn't present ctxR Ec in both water and biofilm samples. The water contamination with ctxR $E c$ ranged from presence (i.e., at least 0.5 bacteria $\times 100 \mathrm{ml}^{-1}$ water) to $9.5 \times 10^{2} \mathrm{CFU} 100 \mathrm{ml}^{-1}$ with the maximum observed at site 3\# in Bligny-sur-Ouche. The same trend was observed for the biofilm with a range varying from below detection limit $(<0.1$ bacteria $\times 100 \mathrm{mg}^{-1}$ biofilm) to $6.6 \times 10^{2} \mathrm{CFU} 100 \mathrm{mg}^{-1}$ (site $6 \#$ in Mâlain). In water samples, the ratio ctxR E. coli/total E. coli varied from less than 1 to $7 \%$, while in biofilm samples, this ratio varied from less than 1 to $22 \%$.

\section{Patterns of Abundance and Distribution of ctxR Ec in Fish Guts in Two Sites of the Ouche River}

One hundred twenty-seven fishes were captured; 20 chubs (Leuciscus cephalus), 23 vairones (Telestes souffia), 12 loaches

TABLE 1 | Number of CFU (Colony Forming Units) of E. coli and ctxR E. coli per $100 \mathrm{ml}^{-1}$ water or per $100 \mathrm{mg}^{-1}$ biofilm; when enrichments were done prior to detection, results were expressed as $\mathrm{P}$ (Presence) or $\mathrm{A}$ (absence) of ctxR E. coli.

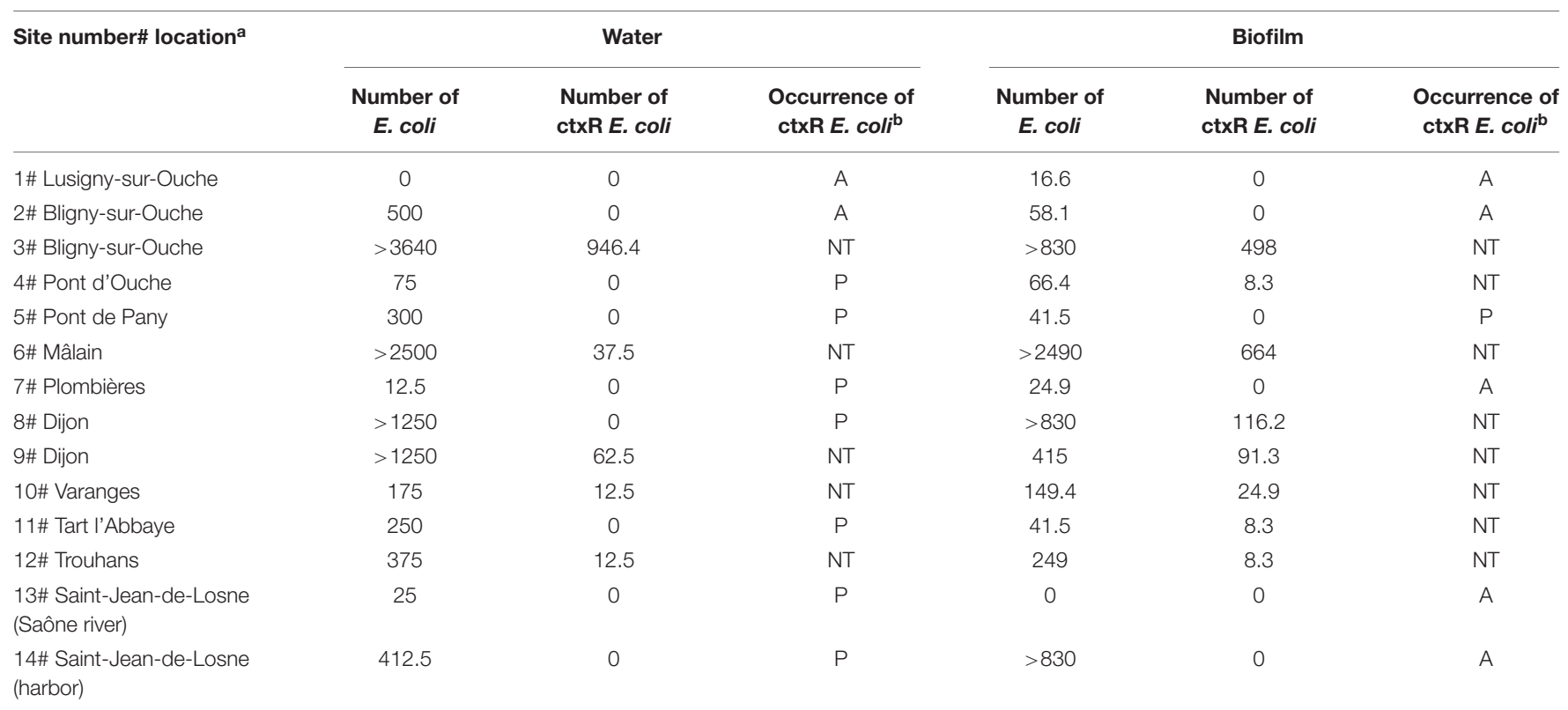

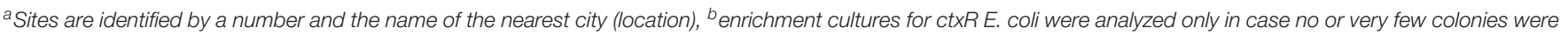
observed after direct plating of samples, NT not tested because colonies were obtained without enrichment. 
TABLE 2 | Number and size range of fishes sampled in the Ouche river.

\begin{tabular}{|c|c|c|c|c|}
\hline \multirow[b]{2}{*}{ Diet type and fish species } & \multicolumn{2}{|c|}{ 8\# Dijon } & \multicolumn{2}{|c|}{ 9\# Dijon } \\
\hline & $\mathbf{N}^{\mathbf{a}}$ & Size range $(\mathrm{cm})$ & $\mathbf{N}^{\mathbf{a}}$ & Size range $(\mathrm{cm})$ \\
\hline Leuciscus cephalus & 13 & $13.7-27.8$ & 7 & $15.2-24.8$ \\
\hline Telestes souffia & 6 & $13.2-17.9$ & 17 & $14.7-19.5$ \\
\hline Phoxinus phoxinus & 10 & $6.4-7.9$ & 11 & $6.9-8.3$ \\
\hline Rutilus rutilus & 6 & $11.5-17.6$ & 0 & \\
\hline \multicolumn{5}{|l|}{ Predator } \\
\hline Barbatula barbatula & 9 & $6.7-8.4$ & 3 & $6.2-7.5$ \\
\hline Cottus gobio & 9 & $8.7-12.2$ & 14 & $9.8-12.3$ \\
\hline Perca fluviatilis & 3 & $13.4-15.4$ & 0 & \\
\hline
\end{tabular}

${ }^{a} \mathrm{~N}$ : number of individuals.

TABLE 3 | Prevalence of total E. coli and ctxR EC among fish species in the Ouche river originated from 2 Dijon sites.

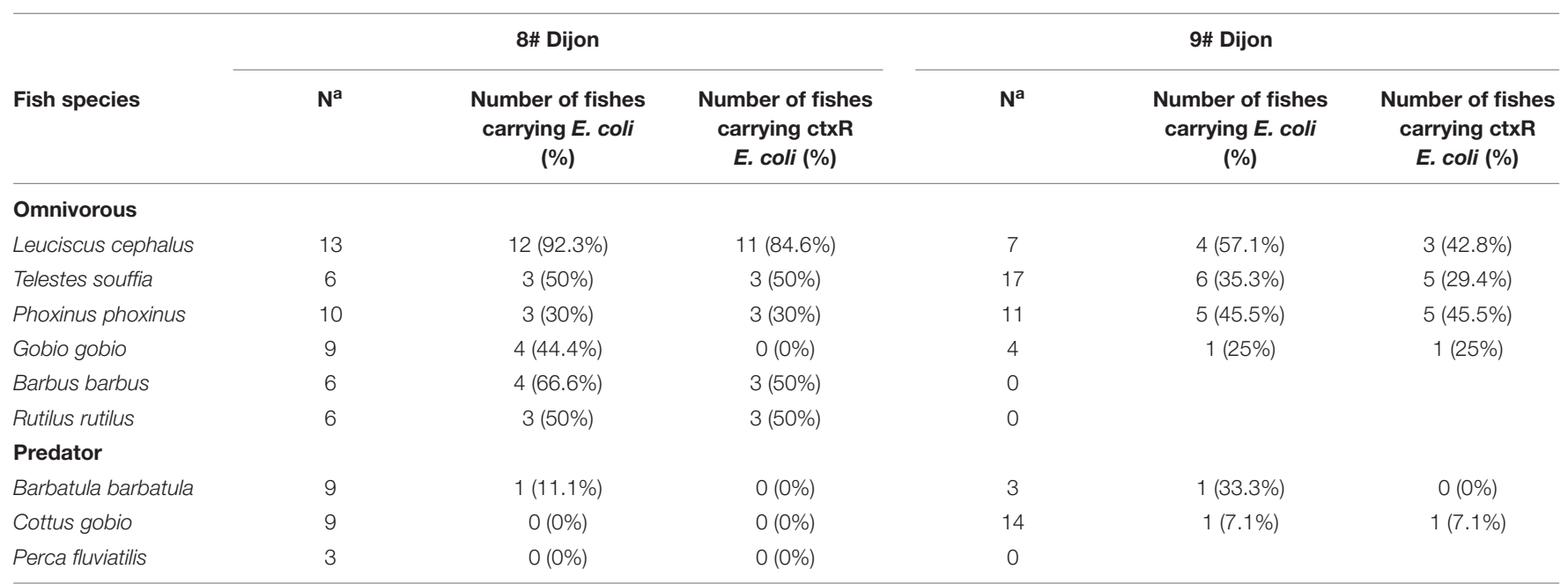

${ }^{a} \mathrm{~N}$ : number of individuals.

(Barbatula barbatula), 21 minnows (Phoxinus phoxinus), 13 gudgeons (Gobio gobio), 23 bullheads (Cottus gobio), 6 barbells (Barbus barbus), 3 perches (Perca fluviatilis), and 6 roaches (Rutilus rutilus). The characteristics of fishes sampled for this study are given in Table 2. Since the prevalence of total E. coli and $c t x R E c$ in fish guts was low, results were expressed as presence or absence of these bacteria after enrichment of the samples. The prevalence of total E. coli and ctxR Ec among fish species and from the two sampling sites is presented in Table 3. Grouping of fish species as omnivorous or predator species is given in Table 2.

No difference was found in fishes between the two sites concerning the prevalence of total E. coli (Fisher's exact test $p=0.5493$ ) and the prevalence of ctxR Ec (Fisher's exact test $p=0.5606$ ). However, in the two sites (Figure 2), prevalence of total E. coli and ctxR Ec between fish species were profoundly variable and seemed strongly influenced by their diet. That is, omnivorous species were significantly more colonized than predator species both for total E. coli (Site 8\#: Fisher's exact test $p<0.0001$, Site 9\#: Fisher's exact test $p=0.0001)$ and $\operatorname{ctxR} E c$

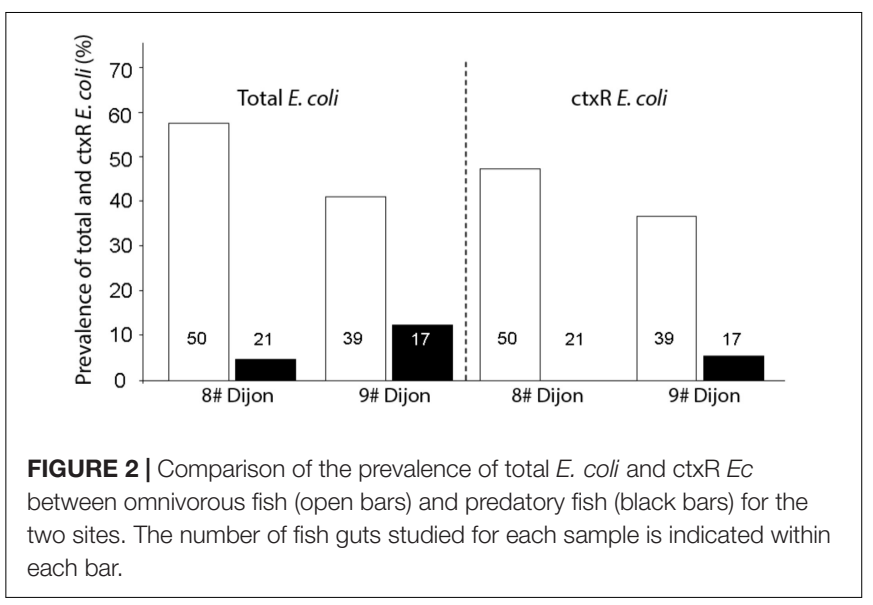

(Site 8\#: Fisher's exact test $p=0.0351$; Site 9\#: Fisher's exact test $p=0.0229)$. 


\section{Phenotyping and Genotyping of ctxR Ec Isolated From Fish Guts and Environmental Samples}

One hundred and twenty ctxR isolates originated from water, biofilm and fish guts were recovered from TBX plates supplemented with cefotaxime used for enumeration or detection of ctxR Ec. Water and biofilm isolates were recovered from the 14 sites and analyzed along the Ouche river, whereas fish isolates originated only from sites eight and nine. Seventythree ctxR isolates were successfully purified and cryo-conserved. Among those, 52 isolates proved to belong to the E. coli species. These 52 isolates were screened for their antibiotic susceptibility and for their ESBL phenotype. Among these, 36 isolates were confirmed to produce ESBL (positive for the doubledisk synergy test, and/or because they carried at least one bla ${ }_{C T X-M}$ gene).

Further analyses were performed only on this subset of 36 ESBL-Ec isolates. The antibiotic susceptibility tests revealed that a large proportion of ESBL-Ec isolates were a multidrug resistant (MDR) bacteria (Figure 3). Only 3\% of the strains were only resistant to third generation cephalosporins (3GC) whereas other isolates harbored additional resistance to between 1 to 8 antibiotics. Eighteen percent (18\%) of strains were resistant to six different antibiotics (other than those of the cephalosporin family) and $15 \%$ were resistant to eight different antibiotics (Figure 3). MDR ESBL-Ec seemed to occur in the various habitats tested (environmental or fish gut). Resistance to different antibiotic families was widespread among isolates: i.e., $92 \%$ were resistant to at least one aminoglycoside, $78 \%$ were resistant to doxycycline, $56 \%$ were resistant to cotrimoxazol, $44 \%$ were resistant to at least one quinolone and $28 \%$ were resistant to chloramphenicol.

Genotyping of the 36 ESBL-Ec isolates that originated from water (14 isolates), biofilm (10 isolates), and fish (12 isolates) along Ouche, were revealed using MLST, and the results are given in Table 4. Among this set of 36 isolates, MLST analysis revealed 22 different sequence types (ST) that can be grouped into seven clonal complexes. Clonal complexes 10 and 23 are the most frequently encountered (respectively 7 and 9 strains out of 36 strains tested) although other clonal complexes are

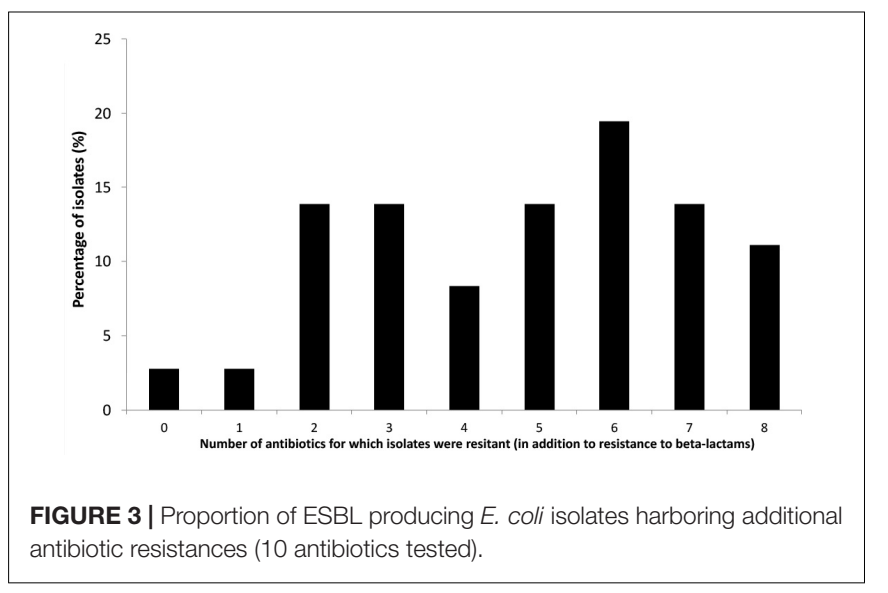

encountered only once. Eleven STs were not affiliated to any clonal complex. Most frequently encountered STs (i.e., ST10 and ST410) were isolated from the three habitats. ST 10 (5554 strains recorded in Enterobase) is a ST encountered worldwide and has frequently been reported in water environments. ST410 (421 strains recorded in Enterobase) is also commonly encountered in water environments. Among these 22 different described STs, 17 STs were already found to occur in water environments (as indicated in Enterodatabase). Noticeably, one isolate originating from a bullhead gut at site 9\# in Dijon, belonged to ST 131, which grouped clinical ESBL-Ec strains commonly involved in human urinary tract infections and bacteremia worldwide (Table 4).

Eighty-six ESBL-Ec isolates originating from effluents of the eight WWTP discharging into Ouche river, typed by MLST (Hartmann, personal communication), were compared to environmental strains obtained in this study. WWTP isolates belonged to 28 different STs (Figure 4). Sequence type ST10 was the most frequently encountered ST among WWTP isolates, similar to that observed among the Ouche isolates. ST10 was present in five of the eight WWTP studied. Seven STs occurring in the WWTP effluents were also encountered in the Ouche samples (biofilm, water or fish). However, 14 different STs (including the frequently detected ST410) occurring in the Ouche isolates did not occur in the WWTP effluents. The phylogenetic tree produced from one strain of each ST encountered in the WWTP effluent, water, biofilm or fish gut (Figure 5) reveals a huge diversity in ESBL-Ec strains, no ST or clonal complex seemed to be linked with the origin of the sample.

Occurrence of bla $a_{C T X-M}$ genes and the intll gene in the 36 ESBL-Ec isolates were determined by PCR. The bla $a_{C T X-M}$ gene type was determined for each strain by Sanger sequencing (Table 4). Four different bla $a_{\mathrm{CTX}-\mathrm{M}}$ genes (blaCTX-M1,14,15,27) were observed among the set of 36 isolates. These genes belonged to the two major bla $a_{\mathrm{CTX}-\mathrm{M}}$ coding CTX-M group 1 and CTX-M group 9.

No significant difference was found in the proportion of bla СTX-M coding CTX-M group 1 and CTX-M group 9 between the isolates coming from water, biofilm and fish guts $\left(\chi^{2}{ }_{2}=3.07\right.$, $p=0.2151)$. Similarly, among the bla $a_{\mathrm{CTX}-\mathrm{M}}$ coding CTX-M group 1, no difference was found in the proportion of $b a_{\mathrm{CTX}-\mathrm{M} 1}$ and $b a_{\mathrm{CTX}-\mathrm{M} 15}$ between the isolates from water, biofilm and fish $\left(\chi^{2}{ }_{2}=2.18, p=0.3360\right)$.

Sequences showing $100 \%$ identity with the intl1 sequence occurred in $53 \%$ of the strains (Table 4 ).

\section{DISCUSSION}

The objectives of the study were to monitor the occurrence of total E. coli and ESBL-Ec in a small watershed (Ouche river) targeting environmental matrices (water, biofilm) as well as fishes that live in the aquatic ecosystem. This watershed is impacted by anthropic activities, i.e., urban wastewater treatment but also by farm effluents that might also impact bacteriological water quality of the river. 
TABLE 4 | Genotyping of ESBL producing E. coli originated from the Ouche river.

\begin{tabular}{|c|c|c|c|c|c|}
\hline Strain number ${ }^{a}$ & Sampling site ${ }^{b}$ & Habitat & $\begin{array}{l}\text { Sequence Type (clonal } \\
\text { complex when existing) }\end{array}$ & $\begin{array}{c}\text { bla }_{\mathrm{CTX}-\mathrm{M}} \text { gene (CTX-M } \\
\text { group) }\end{array}$ & $\begin{array}{l}\text { Occurence of intl1 } \\
\text { sequence }^{c}\end{array}$ \\
\hline MIAE02070 & 6\# Mâlain & Biofilm & $10(10)$ & $15(1)$ & - \\
\hline MIAE02071 & 8\# Dijon & Biofilm & 212 & $1(1)$ & + \\
\hline MIAE02072 & 9\# Dijon & Biofilm & $38(38)$ & $27(9)$ & - \\
\hline MIAE02073 & 9\# Dijon & Biofilm & 367 (23) & $1(1)$ & + \\
\hline MIAE02074 & 9\# Dijon & Biofilm & 540 & $1(1)$ & + \\
\hline MIAE02075 & 9\# Dijon & Biofilm & 1850 & $1(1)$ & + \\
\hline MIAE02076 & 9\# Dijon & Biofilm & $367(23)$ & $1(1)$ & + \\
\hline MIAE02077 & 9\# Dijon & Biofilm & $410(23)$ & $15(1)$ & - \\
\hline MIAE02078 & 9\# Dijon & Biofilm & 2851 & $15(1)$ & + \\
\hline MIAE02079 & 9\# Dijon & Biofilm & 1167 & $1(1)$ & - \\
\hline MIAE02080 & 9\# Dijon & Biofilm & $410(23)$ & $15(1)$ & - \\
\hline MIAE02081 & 9\# Dijon & Biofilm & $10(10)$ & $1(1)$ & + \\
\hline MIAE02082 & 10\# Varanges & Biofilm & $181(168)$ & $14(9)$ & - \\
\hline MIAE02083 & 10\# Varanges & Biofilm & $23(23)$ & $14(9)$ & + \\
\hline MIAE02084 & 3\# Bligny-sur-Ouche & Water & $10(10)$ & $1(1)$ & + \\
\hline MIAE02085 & 4\# Pont d'Ouche & Water & $410(23)$ & $1(1)$ & - \\
\hline MIAE02086 & 6\# Mâlain & Water & 1431 & $15(1)$ & + \\
\hline MIAE02087 & 8\# Dijon & Water & $10(10)$ & $15(1)$ & + \\
\hline MIAE02088 & 9\# Dijon & Water & 1196 & $1(1)$ & - \\
\hline MIAE02089 & 11\# Tart l'Abbaye & Water & $69(69)$ & $15(1)$ & + \\
\hline MIAE02090 & 11\# Tart l'Abbaye & Water & 457 & $14(9)$ & - \\
\hline MIAE02091 & 13\# Saint-Jean-de-Losne & Water & 744 & $1(1)$ & - \\
\hline MIAE02092 & 14\# Saint-Jean-de-Losne & Water & $90(23)$ & $15(1)$ & + \\
\hline MIAE02093 & 14\# Saint-Jean-de-Losne & Water & $90(23)$ & $15(1)$ & + \\
\hline MIAE02094 & 8\# Dijon & Fish - roach & $38(38)$ & $15(1)$ & - \\
\hline MIAE02095 & 8\# Dijon & Fish - chub & $131(131)$ & $1(1)$ & - \\
\hline MIAE02096 & 8\# Dijon & Fish - chub & $617(10)$ & $15(1)$ & + \\
\hline MIAE02097 & 8\# Dijon & Fish - chub & $617(10)$ & $15(1)$ & + \\
\hline MIAE02098 & 9\# Dijon & Fish - vairone & $38(38)$ & $27(9)$ & - \\
\hline MIAE02099 & 9\# Dijon & Fish - vairone & $410(23)$ & $14(9)$ & - \\
\hline MIAE02100 & 9\# Dijon & Fish - vairone & 362 & $14(9)$ & - \\
\hline MIAE02101 & 9\# Dijon & Fish - vairone & 362 & $14(9)$ & - \\
\hline MIAE02102 & 9\# Dijon & Fish - vairone & 540 & $1(1)$ & + \\
\hline MIAE02103 & 9\# Dijon & Fish - minnow & 354 (354) & $14(9)$ & + \\
\hline MIAE02104 & 9\# Dijon & Fish -minnow & 357 & $15(1)$ & - \\
\hline MIAE02105 & 9\# Dijon & Fish - chub & $10(10)$ & $15(1)$ & + \\
\hline
\end{tabular}

a Strain numbers are from the MIAE collection hosted at INRA Dijon, UMR Agroecologie.

b Site 13\# is water from the Saône river at Saint-Jean-de-Losne and site \#14 is water from the Saint-Jean-de-Losne harbor.

${ }^{c}+$ Presence, - absence.

\section{Environmental Dissemination of ctxR Ec and Particularly of ESBL-EC}

First, water sampling revealed the presence of $E$. coli all along the Ouche river, at all sampling sites excepted from the river source. Interestingly, ctxR Ec contaminations of water and biofilm appeared downstream from the first WWTP discharge in the Ouche river (site \#3 in Bligny-sur-Ouche, Figure 1). Thus, our observations confirm that WWTP are probably the main source point of water contamination by $c t x R E c$ (Blaak et al., 2014; Brechet et al., 2014). Among ctxR Ec isolates, at least $69 \%$ produced a CTX-M type ESBL. The other strains (not showing
ESBL phenotype) may produce cephalosporinases or other betalactamases. The Ouche watershed ecosystem contamination by ESBL-Ec seems to be linked to WWTP discharge, which is in agreement with previously published data indicating that discharge of treated wastewater is a source point of ESBL$E c$ for freshwater ecosystems (Brechet et al., 2014; Czekalski et al., 2014; Vivant et al., 2016). ESBL-Ec might thus serve as an indicator of the anthropic impact (urban or farming) in aquatic ecosystems. The ratio of ctxR Ec/total E. coli seems to be overall higher in biofilm samples than in water samples, thus highlighting the role of biofilm as a potent reservoir for ctxR Ec. 


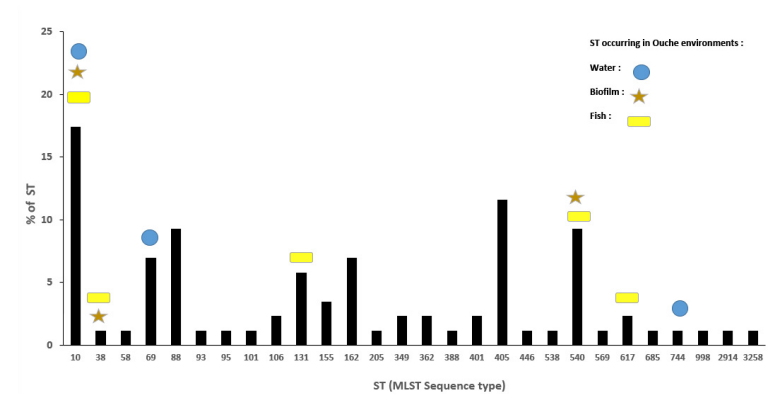

FIGURE 4 | Distribution of ST (\%) encountered in the eight WWTP effluents discharging into the Ouche river and their occurrence in environmental samples: water, biofilm, and fish guts.

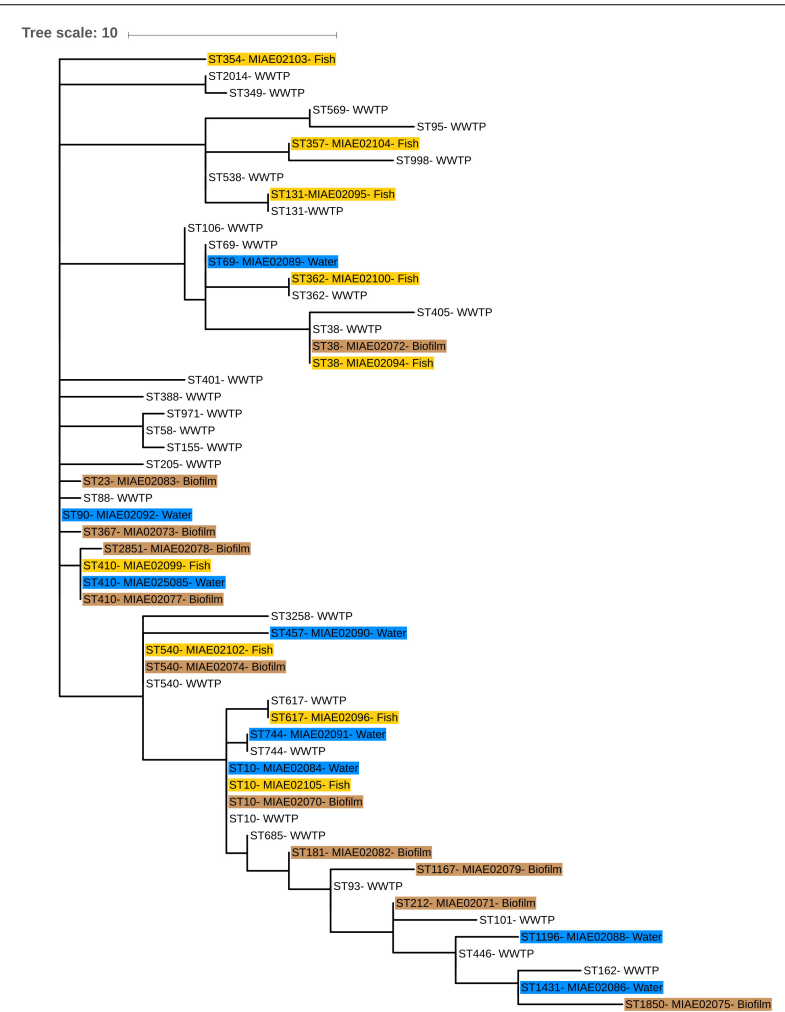

FIGURE 5 | Phylogenetic minimum spanning tree (MS tree) based on MLST sequences of seven housekeeping genes from environmental and WWTP effluents strains. ST numbers from environmental strains are followed by isolate number (see Table 4) and water, biofilm, and fish isolates are highlighted in blue, brown, and yellow, respectively. Only ST number is given for WWTP effluents isolates.

\section{Prevalence of Total E. coli and ctxR Ec in Fish Guts}

Prevalence of total E. coli in fish guts varied from 0 to $92 \%$ across fish species. Our study revealed that fish diet (predator or omnivore) might significantly influence the prevalence of total E. coli as well as ctxR Ec. To our knowledge, this is the first description of the occurrence of ESBL-Ec in freshwater fishes in France. Our findings agree with previous work showing the occurrence of ESBL-Ec in fishes from Swiss lakes (Abgottspon et al., 2014; Zurfluh et al., 2015). Several studies have already shown the presence of ESBL-Ec in fish from farmed (Jiang et al., 2012) or wild population in Asia (Hon et al., 2016) and in Africa (Moremi et al., 2016). Although E. coli does not seem to be a permanent inhabitant of fish guts (Austin, 2006), these bacteria are able to colonize the fish gut, especially in omnivorous fishes that, at least partially, feed from contaminated biofilms. The higher ratio of ctxR Ec/total E. coli in biofilm samples compared to water might thus also explain the higher contamination of omnivorous fishes by $c t x R$ Ec and ESBL-Ec. Further studies are needed, including time lapse survival of ESBL-Ec in the gut of various fish species (omnivorous or predatory), to explore the adaptation of E. coli and ESBL-Ec to fish gut and potential contamination of fish muscles.

In our survey, the three species of wild predatory fish harbored very little contamination by ESBL-Ec. This could be explained by the anatomy and physiology of these species. Indeed, as for most animals, predatory fishes have significantly shorter guts than omnivorous or herbivorous fishes (Keith and Allardi, 2001). This physical characteristic could be less conducive to the survival and persistence of bacteria. Moreover, high gastric acidity of predator fishes could also play a significant role in the lack of persistence of these bacteria. For example, Western (Western, 1971) showed that in C. gobio the gastric contents were maintained at $\mathrm{pH} 2.0$ while food remains in the stomach. However, such acidity could not be sufficient to reduce the number of $E$. coli. Indeed, Foster (Foster, 2004) showed that E. coli could resist in strongly acidic environments.

Finally, the difference in the number of ESBL- $E c$ between predator and omnivorous fishes may be explained by a combination of two parameters. First, their feeding behavior could be a first filter to contamination, with omnivorous species more susceptible to be contaminated than predatory species, combined with a second filter represented by the difference in the length of their gut, less favorable to the persistence of bacteria in predators.

\section{Genotyping Analysis}

Our study highlighted a noticeable diversity of ESBL-Ec, since 22 different STs were detected among the set of 36 environmental and fish isolates analyzed. Some STs (mainly ST10) seem to be ubiquitous and are detected in both environmental and WWTP isolates. However, some STs (namely ST410 and 13 others) occurred only in environmental ESBL-Ec and not in those from WWTP effluents. This result might indicate the presence of other sources for ESBL-Ec: i.e., farming activities, livestock effluents, manure application in fields. We demonstrated that $b a_{\mathrm{CTX}-\mathrm{M}}$ genes that are dominant in clinical isolates (Sauget et al., 2016), namely bla $a_{\mathrm{CTX}-\mathrm{M} 1}, b l a_{\mathrm{CTX}-\mathrm{M} 15}$ and bla $a_{\mathrm{CTXM14}}$, also occurred in environmental and fish isolates. No obvious correlation was observed between the ESBL-Ec ST and the type of bla $a_{\mathrm{CTX}-\mathrm{M}}$ gene carried or with the presence of the intll gene sequence. One fish gut isolate belonged to the well-known ST131 that groups clinical epidemic clones (Sauget et al., 2016) thus indicating that this genotype might occur and/or persist in the environment. 
The genetic diversity of ESBL-Ec did not seem to corelate with a special habitat or with a sampling site. Whatever the source of our strains, all these STs were already described in a large diversity of habitats and hosts. These STs could group isolates either pathogenically or not for Humans (see text footnote ${ }^{2}$ ).

Although there was no obvious relationship between the occurrence of the intl1 sequence and the multi-resistance phenotype, the potential presence of class 1 integrons in half of the strains might explain the MDR phenotype of some isolates. Further complete sequencing of these integrons might shed light on their potential role in the antibiotic resistance phenotype of environmental strains. Indeed, Gillings et al. (2015) proposed to use the class 1 integron-integrase gene as a potential marker of the anthropic impact on the environment (anthropogenic pollution). Occurrence of clinical class 1 integrons in our strains obviously indicates their human origin and thus reinforces the hypothesis that the main origin of this contamination is due to effluent discharge from WWTP. Such discharges can induce serious public health problems. Indeed, these resistant strains found in freshwater environments might contribute to antibiotic resistance currently spreading in the human population, through the consumption of fish, or by water reuse for crop irrigation, or through recreational activities (bathing). Moreover, aquatic environments might act as long term or permanent reservoirs for antibiotic resistant bacteria and/or antibiotic resistance genes. Indeed, in their review, Marti et al. (2014) pointed out that bacteria found in natural aquatic ecosystems are organized in biofilms, which facilitate their survival, dispersal, but also, due to high cell density and close proximity, the possible horizontal gene transfer (HGT) between bacteria. Thus, biofilms can serve as long-term reservoirs for antibiotic resistant genes and contribute to the emergence and the dissemination of multi resistant strains.

In this scheme, fishes, and especially fishes that feed on biofilm, could host strains and might be sentinels of environmental contamination through antibiotic resistant bacteria. However, further studies are needed to evaluate the duration of survival of ESBL-Ec in the environment and in fish guts. Finally, the fitness of ESBL-Ec versus wild type E. coli under environmental and fish gut conditions should be analyzed.

\section{REFERENCES}

Abgottspon, H., Nuesch-Inderbinen, M. T., Zurfluh, K., Althaus, D., Hachler, H., and Stephan, R. (2014). Enterobacteriaceae with extended-spectrum- and pAmpC-type beta-lactamase-encoding genes isolated from freshwater fish from two lakes in Switzerland. Antimicrob. Agents Chemother. 58, 2482-2484. doi: 10.1128/aac.02689-13

Alikhan, N.-F., Zhou, Z., Sergeant, M. J., and Achtman, M. (2018). A genomic overview of the population structure of Salmonella. PLoS Genet. 14:e1007261. doi: 10.1371/journal.pgen.1007261

Austin, B. (2006). The bacterial microflora of fish, revised. Sci. World J. 6, 931-945. doi: 10.1100/tsw.2006.181

Blaak, H., Lynch, G., Italiaander, R., Hamidjaja, R. A., Schets, F. M., and Husman, A. M. D. (2015). Multidrug-resistant and extended spectrum beta-lactamaseproducing Escherichia coli in Dutch surface water and wastewater. PLoS One 10:e0127752. doi: 10.1371/journal.pone.0127752

Blaak, H., van Hoek, A. H. A. M., Veenman, C., van Leeuwen, A. E. D., Lynch, G., van Overbeek, W. M., et al. (2014). Extended spectrum beta-lactamase- and
At the same time, this study emphasizes the need for complementary treatments of WWTP effluents (tertiary treatments). These treatments should be implemented in order to decrease the spread of such antibiotic resistant isolates. Various tertiary treatments might be implemented: i.e., constructed wetlands [combination of open water ponds and planted bed filters as described by Vivant et al. (2016)], UV treatment, effluent filtration or ozonation.

\section{ETHICS STATEMENT}

Electrofishing was performed in accordance with the recommendations of the French National Agency for Water and Aquatic Environments (ONEMA) and authorized by the prefecture from Côte d'Or (France). This study conforms to the legal requirements of France. The experiment has received the agreement of the Animal Care and Ethical Committee of the Université de Bourgogne, Dijon, France.

\section{AUTHOR CONTRIBUTIONS}

LB had substantial contributions to the conception or design of the work as well as for the drafting of the manuscript. EB had done the practical work and analyzed the results. GD had substantial contributions to the acquisition, analysis, and interpretation of data for the work and also for the drafting of the manuscript. SM contributed to the acquisition of data. CN revised the manuscript critically for important intellectual content. JM provided approval for publication of the content. $\mathrm{AH}$ had substantial contributions to the conception or design of the work and to the drafting of the manuscript.

\section{FUNDING}

This work was supported by ANSES through the PNR EST program CIREC grant 2013-1-254.

constitutively AmpC-producing Enterobacteriaceae on fresh produce and in the agricultural environment. Int. J. Food Microbiol. 168, 8-16. doi: 10.1016/ j.ijfoodmicro.2013.10.006

Bonnedahl, J., Drobni, M., Gauthier-Clerc, M., Hernandez, J., Granholm, S., Kayser, Y., et al. (2009). Dissemination of Escherichia coli with CTX-M type ESBL between humans and yellow-legged gulls in the south of France. PLoS One 4:e5958. doi: 10.1371/journal.pone.0005958

Bonnedahl, J., Drobni, P., Johansson, A., Hernandez, J., Melhus, A., Stedt, J., et al. (2010). Characterization, and comparison, of human clinical and blackheaded gull (Larus ridibundus) extended-spectrum beta-lactamase-producing bacterial isolates from Kalmar, on the southeast coast of Sweden. J. Antimicrob. Chemother. 65, 1939-1944. doi: 10.1093/jac/dkq222

Bonnet, R. (2004). Growing group of extended-spectrum beta-lactamases: the CTX-M enzymes. Antimicrob. Agents Chemother. 48, 1-14. doi: 10.1128/aac. 48.1.1-14.2004

Brahmi, S., Touati, A., Dunyach-Remy, C., Sotto, A., Pantel, A., and Lavigne, J. P. (2018). High prevalence of extended-spectrum -lactamaseproducing Enterobacteriaceae in wild fish from the Mediterranean 
sea in Algeria. Microb. Drug Resist. 24, 290-298. doi: 10.1089/mdr. 2017.0149

Brechet, C., Plantin, J., Sauget, M., Thouverez, M., Talon, D., Cholley, P., et al. (2014). Wastewater treatment plants release large amounts of extendedspectrum beta-lactamase-producing Escherichia coli into the environment. Clin. Infect. Dis. 58, 1658-1665. doi: 10.1093/cid/ciu190

Carter, D. L., Docherty, K. M., Gill, S. A., Baker, K., Teachout, J., and Vonhof, M. J. (2018). Antibiotic resistant bacteria are widespread in songbirds across rural and urban environments. Sci. Total Environ. 627, 1234-1241. doi: 10.1016/j. scitotenv.2018.01.343

CLSI (2012a). Methods for Antimicrobial Susceptibility Testing of Anaerobic Bacteria: Approved Standard. CLSI Document M11-A8. 8th Edn. Wayne, PA: Clinical and Laboratory Standards Institute.

CLSI (2012b). Performance Standards for Antimicrobial Susceptibility Testing Twenty-Second Information Supplement M100-S22. Wayne, PA: Clinical and Laboratory Standards Institute.

Costa, D., Poeta, P., Saenz, Y., Vinue, L., Rojo-Bezares, B., Jouini, A., et al. (2006). Detection of Escherichia coli harbouring extended-spectrum beta-lactamases of the CTX-M, TEM and SHV classes in faecal samples of wild animals in Portugal. J. Antimicrob. Chemother. 58, 1311-1312. doi: 10.1093/jac/dkl415

Czekalski, N., Diez, E. G., and Burgmann, H. (2014). Wastewater as a point source of antibiotic-resistance genes in the sediment of a freshwater lake. ISME J. 8, 1381-1390. doi: 10.1038/ismej.2014.8

Foster, J. W. (2004). Escherichia coli acid resistance: tales of an amateur acidophile. Nat. Rev. Microbiol. 2, 898-907. doi: 10.1038/nrmicro1021

Franz, E., Veenman, C., van Hoek, A. H. A. M., Husman, A. D., and Blaak, H. (2015). Pathogenic Escherichia coli producing extended-spectrum beta-lactamases isolated from surface water and wastewater. Sci. Rep. 5:14372. doi: $10.1038 /$ srep 14372

Garner, P. (1996). Microhabitat use and diet of 0+ cyprinid fishes in a lentic, regulated reach of the River Great Ouse, England. J. Fish Biol. 48, 367-382. doi: 10.1111/j.1095-8649.1996.tb01434.x

Gillings, M. R., Gaze, W. H., Pruden, A., Smalla, K., Tiedje, J. M., and Zhu, Y.-G. (2015). Using the class 1 integron-integrase gene as a proxy for anthropogenic pollution. ISME J. 9, 1269-1279. doi: 10.1038/ismej.2014.226

Goncalves, A., Igrejas, G., Radhouani, H., Estepa, V., Pacheco, R., Monteiro, R., et al. (2012). Iberian wolf as a reservoir of extended-spectrum beta-lactamaseproducing Escherichia coli of the TEM, SHV, and CTX-M groups. Microb. Drug Resist. 18, 215-219. doi: 10.1089/mdr.2011.0145

Guenther, S., Ewers, C., and Wieler, L. H. (2011). Extended-spectrum betalactamases producing $E$. coli in wildlife, yet another form of environmental pollution? Front. Microbiol. 2:246. doi: 10.3389/fmicb.2011.00246

Hartmann, A., Locatelli, A., Amoureux, L., Depret, G., Jolivet, C., Gueneau, E., et al. (2012). Occurrence of CTX-M producing Escherichia coli in soils, cattle, and farm environment in France (Burgundy Region). Front. Microbiol. 3:83. doi: $10.3389 /$ fmicb. 2012.00083

Hon, N. T. N., Hoa, T. T. T., Thinh, N. Q., Hinenoya, A., Nakayama, T., Harada, K., et al. (2016). Spread of antibiotic and antimicrobial susceptibility of ESBLproducing Escherichia coli isolated from wild and cultured fish in the Mekong delta, Vietnam. Fish Pathol. 51, S75-S82. doi: 10.3147/jsfp.51.S75

Hyslop, E. J. (1982). The feeding habits of stone loach, Noemacheilus bavbatulus (L.), and bullhead, Cottus gobio L. J. Fish Biol. 21, 187-196. doi: 10.1111/j.10958649.1982.tb03998.x

Jarlier, V., Nicolas, M. H., Fournier, G., and Philippon, A. (1988). Extended broadspectrum beta-lactamases conferring transferable resistance to newer betalactam agents in Enterobacteriaceae - hospital prevalence and susceptibility patterns. Rev. Infect. Dis. 10, 867-878. doi: 10.1093/clinids/10.4.867

Jiang, H. X., Tang, D. A., Liu, Y. H., Zhang, X. H., Zeng, Z. L., Xu, L., et al. (2012). Prevalence and characteristics of beta-lactamase and plasmid-mediated quinolone resistance genes in Escherichia coli isolated from farmed fish in China. J. Antimicrob. Chemother. 67, 2350-2353. doi: 10.1093/jac/dks250

Keith, P., and Allardi, J. (2001). Atlas des Poissons D'eau Douce de France. Paris: Muséum National d'Histoire Naturelle.

Letunic, I., and Bork, P. (2016). Interactive tree of life (iTOL) v3: an online tool for the display and annotation of phylogenetic and other trees. Nucleic Acids Res. 44, W242-W245. doi: 10.1093/nar/gkw290

Leverstein-van Hall, M. A., Dierikx, C. M., Cohen Stuart, J., Voets, G. M., van den Munckhof, M. P., van Essen-Zandbergen, A., et al. (2011). Dutch patients, retail chicken meat and poultry share the same ESBL genes, plasmids and strains. Clin. Microbiol. Infect. 17, 873-880. doi: 10.1111/j.1469-0691.2011.03497.x

Literak, I., Dolejska, M., Cizek, A., Djigo, C. A. T., Konecny, A., and Koubek, P. (2009). Reservoirs of antibiotic-resistant Enterobacteriaceae among animals sympatric to humans in Senegal: extended-spectrum beta-lactamases in bacteria in a black rat (Rattus rattus). Afr. J. Microbiol. Res. 3, 751-754.

Literak, I., Dolejska, M., Radimersky, T., Klimes, J., Friedman, M., Aarestrup, F. M., et al. (2010). Antimicrobial-resistant faecal Escherichia coli in wild mammals in central Europe: multiresistant Escherichia coli producing extended-spectrum beta-lactamases in wild boars. J. Appl. Microbiol. 108, 1702-1711. doi: 10.1111/ j.1365-2672.2009.04572.x

Livermore, D. M., and Hawkey, P. M. (2005). CTX-M: changing the face of ESBLs in the UK. J. Antimicrob. Chemother. 56, 451-454. doi: 10.1093/jac/dki239

Maguire, A. J., Brown, D. F. J., Gray, J. J., and Desselberger, U. (2001). Rapid screening technique for class 1 integrons in Enterobacteriaceae and nonfermenting gram-negative bacteria and its use in molecular epidemiology. Antimicrob. Agents Chemother. 45, 1022-1029. doi: 10.1128/Aac.45.4.10221029.2001

Maravic, A., Skocibusic, M., Cvjetan, S., Samanic, I., Fredotovic, Z., and Puizina, J. (2015). Prevalence and diversity of extended-spectrum-betalactamase-producing Enterobacteriaceae from marine beach waters. Mar. Pollut. Bull. 90, 60-67. doi: 10.1016/j.marpolbul.2014.11.021

Marti, E., Variatza, E., and Balcazar, J. L. (2014). The role of aquatic ecosystems as reservoirs of antibiotic resistance. Trends Microbiol. 22, 36-41. doi: 10.1016/j. tim.2013.11.001

Mohsin, M., Raza, S., Schaufler, K., Roschanski, N., Sarwar, F., Semmler, T., et al. (2017). High prevalence of CTX-M-15-Type ESBL-producing E. coli from migratory avian species in Pakistan. Front. Microbiol. 8:2476. doi: 10.3389/ fmicb.2017.02476

Moremi, N., Manda, E. V., Falgenhauer, L., Ghosh, H., Imirzalioglu, C., Matee, M., et al. (2016). Predominance of CTX-M-15 among ESBL producers from environment and fish gut from the shores of Lake Victoria in Mwanza, Tanzania. Front. Microbiol. 7:1862. doi: 10.3389/fmicb.2016.01862

Nicholas, K. B., and Nicholas, H. B. Jr. (1997). GeneDoc: A Tool for Editing and Annotating Multiple Sequence Alignments. Available at: http://www.psc.edu/ biomed/genedoc

Pereira, A., Santos, A., Tacao, M., Alves, A., Henriques, I., and Correia, A. (2013). Genetic diversity and antimicrobial resistance of Escherichia coli from Tagus estuary (Portugal). Sci. Total Environ. 461, 65-71. doi: 10.1016/j.scitotenv.2013. 04.067

Poirel, L., Potron, A., De La Cuesta, C., Cleary, T., Nordmann, P., and MunozPriceb, L. S. (2012). Wild coastline birds as reservoirs of broad-spectrum-betalactamase-producing Enterobacteriaceae in Miami Beach, Florida. Antimicrob. Agents Chemother. 56, 2756-2758. doi: 10.1128/aac.05982-11

Popova, O. A., and Sytina, L. A. (1977). Food and feeding relation of Eurasian perch (Perca fluviatilis) and pikeperch (Stizostedion lucioperca) in various waters of the USSR. J. Fish. Res. Board Can. 34, 1559-1570. doi: 10.1139/f77-219

Reinthaler, F. F., Feierl, G., Galler, H., Haas, D., Leitner, E., Mascher, F., et al. (2010). ESBL-producing E. coli in Austrian sewage sludge. Water Res. 44, 1981-1985. doi: 10.1016/j.watres.2009.11.052

Sabate, M., Miro, E., Navarro, F., Verges, C., Aliaga, R., Mirelis, B., et al. (2002). Beta-lactamases involved in resistance to broad-spectrum cephalosporins in Escherichia coli and Klebsiella spp. clinical isolates collected between 1994 and 1996, in Barcelona (Spain). J. Antimicrob. Chemother. 49, 989-997. doi: 10.1093/ jac/057

Sauget, M., Cholley, P., Vannier, A., Thouverez, M., Nicolas-Chanoine, M. H., Hocquet, D., et al. (2016). Trends of extended-spectrum beta-lactamaseproducing Escherichia coli sequence type 131 and its H30 subclone in a French hospital over a 15-year period. Int. J. Antimicrob. Agents 48, 744-747. doi: 10.1016/j.ijantimicag.2016.09.023

Schijyen, J. F., Blaak, H., Schets, F. M., and Husman, A. M. D. (2015). Fate of extended-spectrum beta-lactamase-producing Escherichia coli from faecal sources in surface water and probability of human exposure through swimming. Environ. Sci. Technol. 49, 11825-11833 doi: 10.1021/acs.est. 5b01888

Stokes, H. W., and Gillings, M. R. (2011). Gene flow, mobile genetic elements and the recruitment of antibiotic resistance genes into gram-negative pathogens. FEMS Microbiol. Rev. 35, 790-819. doi: 10.1111/j.1574-6976.2011.00273.x 
Tacao, M., Correia, A., and Henriques, I. (2012). Resistance to broadspectrum antibiotics in aquatic systems: anthropogenic activities modulate the dissemination of blaCTX-M-like genes. Appl. Environ. Microbiol. 78, 4134-4140. doi: 10.1128/AEM.00359-12

Taylor, N. G. H., Verner-Jeffreys, D. W., and Baker-Austin, C. (2011). Aquatic systems: maintaining, mixing and mobilising antimicrobial resistance? Trends Ecol. Evol. 26, 278-284. doi: 10.1016/j.tree.2011.03.004

Tenover, F. C. (2006). Mechanisms of antimicrobial resistance in bacteria. Am. J. Infect. Control 34, S3-S10. doi: 10.1016/j.ajic.2006.05.219

Vittecoq, M., Godreuil, S., Prugnolle, F., Durand, P., Brazier, L., Renaud, N., et al. (2016). Antimicrobial resistance in wildlife. J. Appl. Ecol. 53, 519-529. doi: 10.1111/1365-2664.12596

Vivant, A. L., Boutin, C., Prost-Boucle, S., Papias, S., Hartmann, A., Depret, G., et al. (2016). Free water surface constructed wetlands limit the dissemination of extended-spectrum beta-lactamase producing Escherichia coli in the natural environment. Water Res. 104, 178-188. doi: 10.1016/j.watres.2016.08.015

Weatherley, N. S. (1987). The diet and growth of 0-group dace, Leuciscus leuciscus (L.), and roach, Rutilus rutilus (L.), in a lowland river. J. Fish Biol. 30, 237-247. doi: 10.1111/j.1095-8649.1987.tb05749.x

Western, J. R. H. (1971). Feeding and digestion in two cottid fishes, freshwater Cottus gobio L. and the marine Enophrys bubalis (Euphrasen). J. Fish Biol. 3, 225-246. doi: 10.1111/j.1095-8649.1971.tb03667.x

Wirth, T., Falush, D., Lan, R., Colles, F., Mensa, P., Wieler, L. H., et al. (2006). Sex and virulence in Escherichia coli: an evolutionary perspective. Mol. Microbiol. 60, 1136-1151. doi: 10.1111/j.1365-2958.2006.05172.x

Woerther, P.-L., Angebault, C., Lescat, M., Ruppé, E., Skurnik, D., Mniai, A. E., et al. (2010). Emergence and dissemination of extended-spectrum beta-lactamase-producing Escherichia coli in the community: lessons from the study of a remote and controlled population. J. Infect. Dis. 202, 515-523. doi: $10.1086 / 654883$

Zhou, Z., Alikhan, N.-F., Sergeant, M. J., Luhmann, N., Vaz, C., Francisco, A. P., et al. (2017). GrapeTree: visualization of core genomic relationships among 100,000 bacterial pathogens. Genome Res. 28, 1395-1404. doi:10.1101/gr.2323 97.117

Zurfluh, K., Glier, M., Hachler, H., and Stephan, R. (2015). Replicon typing of plasmids carrying bla(CTX-M-15) among Enterobacteriaceae isolated at the environment, livestock and human interface. Sci. Total Environ. 521, 75-78. doi: 10.1016/j.scitotenv.2015.03.079

Zurfluh, K., Hachler, H., Nuesch-Inderbinen, M., and Stephan, R. (2013). Characteristics of extended-spectrum beta-lactamase- and carbapenemaseproducing Enterobacteriaceae Isolates from rivers and lakes in Switzerland. Appl. Environ. Microbiol. 79, 3021-3026. doi: 10.1128/Aem.00054-13

Conflict of Interest Statement: The authors declare that the research was conducted in the absence of any commercial or financial relationships that could be construed as a potential conflict of interest.

Copyright (c) 2019 Bollache, Bardet, Depret, Motreuil, Neuwirth, Moreau and Hartmann. This is an open-access article distributed under the terms of the Creative Commons Attribution License (CC BY). The use, distribution or reproduction in other forums is permitted, provided the original author(s) and the copyright owner(s) are credited and that the original publication in this journal is cited, in accordance with accepted academic practice. No use, distribution or reproduction is permitted which does not comply with these terms. 